\title{
Theorising Creative Industry Management: Rebooting the Woolly Mammoth
}

The overarching intent for this special issue was to showcase research and thinking which highlights the challenges and paradoxes of 'mainstream' management and its applicability (or otherwise) to 'managing' the creative industries. This was an interesting challenge given the stated aim of Management Decision is to '...stimulate the interests of business scholars, leaders, and professional managers around the world', an audience surely interested in management theory and practice, rather than creativity per se. As a consequence, the articles included in this volume focus on observations that take place within the creative industries using the language and conventions of management research and theory. In practical terms, the intention of the editorial team is to avoid the risk of 'telling' creative managers how to do their job, instead helping to identify where management theory may assist the process. Where research is concerned, the objective is to add to advances in current management knowledge and, just as importantly, to identify gaps where management scholars and practitioners might learn from successes, experiences and failures in the management of the Creative Industries. As a case in point, we pose the following question:

Question: What do Hendrik Poinar and Steven Spielberg have in common? Answer: Their interest in Deoxyribonucleic Acid - DNA (or is that DNAsaurs?)

The scientist Hendrik Poinar is a molecular evolutionary geneticist who no longer mocks the Jurassic Park movie theme of cloning extinct animals. Poinar explained in a recent TED talk (Poinar, 2013) that he is now keenly interested in sequencing the genome of the Woolly Mammoth. Specifically, Poinar has extracted DNA from permafrost preserved Woolly Mammoth flesh in his laboratory at McMaster University in Ontario, Canada. His creative intent was to bring this giant mammal back to life, within a 10 year timeframe. Speculating upon the commercial value of this project, investors in a potential 'real' Jurassic Park can now begin to speculate over the commercial value of the successful cloning techniques involved in this creative application of science, patents pending of course.

By contrast, Steven Spielberg, who once observed that he 'dreams' for a living, is now involved in the financing of a fourth Jurassic Park movie, Jurassic World. The Jurassic Park franchise had already grossed more than US $\$ 2$ billion dollars at the box office worldwide by the end of 2013 (Nash Information Services, 2015). At a reported cost of US\$ 232 million, that is a gross margin of over $700 \%$, ignoring the probable substantial income derived from 'merch' (franchised merchandise).

So, who is the creative genius and/or successful manager? If success can be measured in financial terms, then surely Spielberg's collective body of work would qualify, given an estimated box office turnover now exceeding US $\$ 8.5$ billion (Powell, 2013). However, any good management accountant knows that turnover is not the same thing as profit. The same managerial accounting practitioner might also attempt to predict the likely returns for Jurassic World based upon the historic returns of the first three Jurassic adventures. Here the territory may change as the slippery slope into a (trend predicted) loss-making fourth movie (see figure 1) would seem quite probable from a historical accounting perspective. 


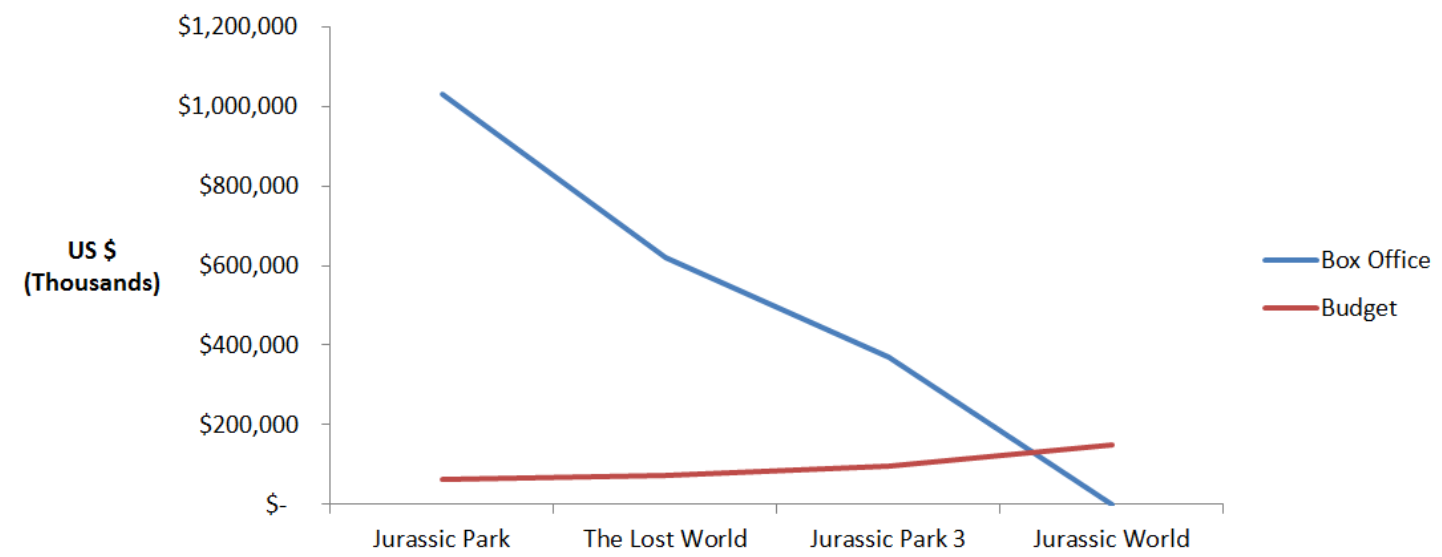

Source: Derived from 'The Numbers' www.the-numbers.com/movies/franchise/Jurassic-Park (Nash Information Services, 2015)

Figure 1: Jurassic Park Franchise, Production Budgets and Box Office Earnings.

In terms of management and creative input, Spielberg produced, financed and directed Jurassic Park as well as The Lost World. In Jurassic Park 3 and Jurassic World, his role is that of Executive Director with the primary task of attracting other investors to the Jurassic franchise, rather than directly investing his own funds. Considering the simplistic trends evident through the plotting of the income and expenses for the Jurassic Park franchise, Spielberg is arguably 'managing' his investment in time and money very well, by passing the investment risk of a failed Jurassic World on to others.

This situation could be described as the archetypical 'exploitation' of the creative by management who develop a strategy to 'monetise' the creative output. This theme of turning creative output into profit is common within the articles that constitute the special issue. What is less evident was an appreciation of the value of the creative individual or the creative collective as the source of innovation (that is, commercial creativity). This is a theme which we return to in the discussion concerning apparent gaps in knowledge and how management theory can be informed by creatives, rather than applied to creatives as is often the case.

Returning to the Jurassic park example, if Jurassic World does become a box office hit that reverses the trend, it is likely the box office success will come from new creative input and/or a new and creative script, as it seems the traditional movie franchise (management) strategy may well be passé now. Perhaps this explains why the fourth movie has had its release date changed by more than four years, with a production budget three times that of the first movie in this franchise.

Shifting focus from the Jurassic Park analogy to consider management theory, we are (paradoxically) somewhat disappointed and at the same time excited by the possibilities this special issue highlights. The field of creative industries management is beset by controversy, ranging from the definition of the creative industries (Banks and O'Connor, 2009), as to whether and how it is different from other industries (Townley et al., 2009) or is characterised by a discourse that sometimes lacks rigour and consistency leading to confusion (Galloway and Dunlop, 2007). While there is a wide body of research with regard to creativity, there is much less dedicated to the development of theory in creative industry management. To date, few studies have focused directly on developing theory about management in the creative industries. Some have focused on theorising about the emergence of new managerial control systems for project teams, in particular examining the emergence of 'post bureaucratic' management, the proponents of which claim that it offers flexibility 
and empowerment (Hodgson and Briand, 2013). Others examine the role of creative industries management in converting intellectual, cultural, social and symbolic capital into economic capital (Townley et al., 2009; Chen et al., 2013).

Extant research points to creative industry management as being complex because the task is to manage creativity and innovation in a context of diverse and fast changing knowledge flows (Jeffcutt and Pratt, 2002). This complexity arises from the wide variety of capital involved in creative production: intellectual capital, social capital, cultural and symbolic capital and how these different types of capital combine in production, distribution, circulation, and consumption (Townley et al., 2009). It seems that creative industry management is simultaneously both mundane and exotic, requiring the imaginative and artistic to operate cheek by jowl with the everyday functions of management control systems.

This requires types of theory that encapsulate an occasionally contradictory situation. Some of the current approaches to research and theory make the assumption that creative industries can simply be considered part of the broader conventional management paradigm. This perspective can be counter-productive as the creative industries often defy definition and conventional analysis (Galloway and Dunlop, 2007). This is because the creative industries tend to occupy the boundaries of current technologies, commodities or ideas (Cunningham, 2009) where there is uncertainty and disruption of conventional practices and understanding (O'Connor, 2011). This is evident in research at the macro-level (McRobbie, 2002) and at the micro level (Boltanski and Chiapello, 2005).

Taking these characteristics into consideration, research and theory building for creative industry management needs to encompass creativity, diversity, imagination and the variable and dissimilar contributions of individuals. This means that it is important to create theories that connect individual (micro) constructs to broader (macro) organisational phenomena. It is, therefore, incumbent on researchers to focus on developing multi-level (meso) theory that take into account management processes that are non-linear and non-uniform. Kozlowski and Klein (2000) identify a typology of multi-level theory from which it seems that the most productive approach in theorising about creative industry management would be to focus on discontinuous compilation. This means looking for emergent variance and patterns of performance, for example, examining adaptability. This requires a focus on the process of emergence of phenomena, rather than its content, and the exploration of interactions of processes that together form an emergent whole.

The development of theory for creative industry management thus requires new thinking. This claim places demands on scholars to understand organisational phenomena and practitioners to be effective in managing them. While doubts have been expressed about the emphasis placed on theory by management researchers (Hambrick, 2007), it remains a central concern for some (Colquitt and Zapata-Phelan, 2007). There is a general agreement about what theory is (or is not), what makes good theory, and the process of theory development Hitt and Smith, 2005; Kozlowski and Klein, 2000; Sutton and Straw, 1995). That said, there remains a need to explore how to better conceptualise theory that enhances the study of management (Corley and Gioia, 2011) and how to cultivate new styles of theory that more effectively address the diversity of phenomena encountered (Delbridge and Fiss, 2013). The need for development concerning 'the process of building some new theory about the work of theory building itself' is important (Corley and Gioia, 2011, p. 19). Furthering such a task is dependent on scholarship based on disciplined imagination that allows us to think better 
(Weick, 1989), add value to current thinking (Whetten, 1989), and alter research practice (LePine and King, 2010).

In this same theme of tension and paradox, we both commend the articles in this special edition as worthy additions to the growing volumes of management theory that can be applied to the Creative Industries and, at the same time, call for greater emphasis on Creative Industry scholars to develop and propose theory, especially at the meso-level. The call for papers asked whether creative industry management was considered an oxymoron or an opportunity - findings from the articles included in this volume indicate that it is probably both.

Given the range of topics included in the volume, it is clear that the call for papers encouraged the inclusion of various management theories in addition to applications of theory in practice within the context of the creative industries. The emerging theme is one of applying what is known to the creative industry context. The articles provide an overview of different fields of management enquiry which may help explain phenomena and challenges observed in the management of enterprise within the Creative Industries.

The articles in this volume are organised as follows: the first article concerns the recruitment and retention of creative managers in a context of remote Australia; the next four articles focus on management practices with regard to creative organisations; creative teams; creative workers and the project management of creative projects. The final two papers in this volume take a more macro approach by investigating the labour precarity of creative workers, with the final paper using a sample group of older workers.

In the first article, Seet, Jones, Acker and Whittle investigate the challenges of Australian indigenous art centre managers. In particular, their investigation concerns the reasons managers of non-Indigenous backgrounds move to, stay in, and leave their positions in Indigenous Art Centres in remote areas of Australia. Utilising a pull-push-shocks perspective, findings indicate that it is mainly the pull factors, related to vocational interests and individual values that are important in explaining why managers take on the challenge of moving to remote Art Centres, with push factors and shocks associated with interviewees' existing jobs playing a lesser role in the decision-making. This article fills a gap in the literature by augmenting the limited field studies that have investigated the recruitment and retention of managers in the creative arts sector in remote areas. Contributions to the literature are evident in the extension of the push-pull theory encompassing aspects of the entrepreneurial career process. The authors refer to centre managers as 'accidental entrepreneurs' since their roles involve innovative and autonomous behaviours and the need to navigate increasingly different business models with both artists and buyers. In addition, "shocks" are also incorporated as catalysts that underpin understanding with regard to career deliberations, an aspect that has not traditionally been studied. Importantly, shocks, in the form of threatening and frightening situations, were especially influential in explaining Art Centre Managers decisions to stay or go. Here the management of creativity is shown to have a very real, contextual and personal aspect. For example, in one case, a manager decided to leave a centre after a physical attack on his young daughter.

The second article, Exploring Boundary-Spanning Practices among Creativity Managers by Anderson, endeavours to build, rather than test, theory. Anderson adopts a practice perspective on boundary spanning and the management of creative teams, arguing that, in times of increasingly dynamic and fluent forms of organisation, organisational capability is 
increasingly dependent on the efficacy and capability of boundary-spanning managerial practice. For instance, Anderson argues that outside organisation boundaries, managerial authority of the creativity process no longer exists and mobilising external resources to participate in the process depends on managers' ability to negotiate, as well as their relational power. Using a case study approach, three types of meta-practices are identified by the authors as important for the managers of creative teams. These are: making room for creativity; defining the creative space and acting in the creative room - all of which are fully explained in the article. The author recommends that if managers systematically address these different practices, it may help them to identify and solve key problems as well as help clarify important boundaries and interfaces with other departments and organisations, thus truly exemplifying boundary spanning within creative organisations.

Knight and Harvey's article - Managing Exploration and Exploitation of Ideas in Creative Organisations - identifies a paradox whereby employees in the creative industries are required to generate new ideas, while being simultaneously committed to delivering standardised processes. The authors refer to exploration, within the context of creative industry, as producing new creative works such as written output and new product development while exploitation includes the reproduction of existing works, established processes and other incremental innovation. Prioritising one process over the other creates competing tensions for management. These tensions are explored through a longitudinal case study conducted in a global media organisation in the creative industry sector. Drawing on data from participant observations, manager interviews, survey instruments and archival documentation, the authors found that creative organisations experience, explore and exploit paradoxes which are nested at three levels: knowledge, learning and motivation. Findings indicated that managers respond to competing tensions through organisational processes that allow differentiation/integration simultaneously. Using paradox theory, Knight and Harvey argue that organisations can achieve long-term sustainability when both exploration and exploitation demands are balanced concurrently and persistently. The authors maintain that their findings are both theoretically and practically important in expanding current understanding of how the synergistic benefits of paradox are reaped by managers at a time when the creative industry is being called on as a source of business innovation.

The fourth article Entrepreneurial Bricolage in Creative Work, by de Klerk, examines the behaviour and performance of actors in creative industry from the perspective of entrepreneurial bricolage, which is defined as making do by applying combinations of the resources at hand to new problems and opportunities. The author maintains that, although to date the implications of bricolage have received relatively little attention in the analysis of entrepreneurial activity, it is directly relevant to the characteristics of start-ups in general and for the creative industries in particular. De Klerk conducted face to face interviews with creative industry entrepreneurs to provide a constructivist view. While not all of the research participants felt comfortable with the word 'entrepreneur', they preferred to use the term 'entrepreneurial behavior' to describe how they had built their own brand and pursued market opportunities. De Klerk labelled efforts of the interviewees to mentor and nurture one another's ability and skills as "collaborative" bricolage which envisaged a long-term outlook and sustained working relationships that transcend immediate work and collaboration. The findings offer insight into the strategic and entrepreneurial connections that advance the profiles of creative actors, using these connections for collaboration, creative work, coinnovation and contribution to mutual skill development. Raising the awareness of bricolage within the creative industries furthers research on the topic while offering an opportunity to 
illustrate how a compete-collaborate-create environment may be beneficial to creative businesses.

The next article, by Gander, examines the design of a recording studio and the impact of this design project upon the recording of creative output (a pop song). It contributes to current literature and practice on the topic of project management in the creative and cultural industries. The research question focuses on how the physical layout and material objects that are present in a recording studio may contribute to the management practices of the music producer during the making of a pop song. To answer the research question, Gander reports on a socio-material study outlining a situational analysis of the practices and participants concerning a musical recording project conducted in a recording studio in the UK. Here, a group of musicians joined with a producer to transform their musical ideas into a marketable product. Gander examines the interaction of the music producer and the musicians through the use of space in both professional studios and home/project studios. The different spatial arrangements between the two types of studios impact on how the creative output comes together and how the producer 'manages' the creative project through his/her relationship with the performer. Findings show that a fundamental aspect contributing to the successful management of creative projects is the way that decision-making is organised during the life of the project, in particular the skills of the project manager are paramount concerning how they absorb challenges to their decisions and organise agreement using a 'fix it in the mix' approach.

The sixth article in the volume, Reducing Labour Precarity in The Creative Industries: Beyond Network Connections, moves the focus onto the creative worker. Farr-Wharton, Brown, Keast and Shymko address the reduction of labour precarity in the creative industries, investigating the impact of organisational business acumen and social network structure on the earnings and labour precarity experienced by creative industry workers. The authors use Burgess and Campbell (1998, p. 7) to define labour precarity as comprising a 'non-continuity of employment, lack of employment protection and exclusion from standard employment benefits'. The authors argue that creative industry workers experience this labour precarity by taking on the business risks otherwise assumed by an employer. Drawing on a sample of 289 creative workers and using structural equation modeling, survey results show that, while the possession of business acumen is a significant enabler for creative workers, social network structure had a partial mediating effect in mitigating labour precarity but no significant effect on perceived earnings. Employing social network theory, the study reveals the relationship between social networks and working conditions in the creative industries. Hence, it fills a gap in knowledge regarding the impact of organisational business acumen and social network structure on the pay and working conditions of people working in a sector that is dominated by self-employed and freelance arrangements. Within this context, resources generated through business acumen have the power to enhance the overall economic outcomes and working conditions that creative workers face.

The final article in this volume concerns the plight of older workers in the Creative Industry in the Netherlands. Hennekan explores the challenges of older self-employed workers in the creative industries and how they deal with these challenges. Like Seet, Jones, Acker and Whittle, Hennekan also uses a pull/push perspective to argue why older workers are increasingly self-employed. The sample group comprises 43 older self-employed creative workers based in the Netherlands. These workers were individuals aged 50 or above planning to start a business, in the process of starting one or have recently started one in the creative industry. Her findings reveal that older self-employed creatives are often forced into self- 
employment where they experience a vicious circle that pushes them away from the creative industry, and they have to deal with multiple identities. Hennekan highlights how selfemployed older creative workers have to integrate their identity as an artist which provides them with work motivation and creative drive with their identity as a "small firm" which enables them to make a living out of being an artist. Hennekan identifies that successful older self-employed creatives deal with these challenges by creating synergies between their identities, focusing on their strengths, use their networks and stress the transferability of their skills and knowledge. Older self-employed workers in the creative industries are a growing and under-researched group; consequently, this article contributes by identifying the challenges of older self-employed creatives and, secondly, presents an overview of the strategies they use to deal with them.

This special issue is a response to Hambrick's call for publishing work with potential for "...identifying empirical patterns that cry out for future research and theorising" (Hambrick, 2007, p. 1350). Miller (2007) refers to the "straightjacket" approach of many top-tier journals which leads to restrictions and "topics that fit neatly within today's popular theories and allow the development and tweaking of those theories" (Miller et al., 2009, p. 278). The special volume team is grateful that there was no such straightjacket in place during the guest editing process, allowing a broad exploration of topics related to management in the creative industries.

Reflecting upon the emergent themes, we envision potential research directions that build or apply theory that is relevant to, and about, creative industry management. For example, the boundary spanning capabilities described by Andersen and Kragh may highlight a potential investigation into how someone like Spielberg 'makes room' for creativity on the set of a movie. Indeed, Spielberg is likely to be an exemplar case of creative industry collaborative bricolage (see the article by de Klerk) or perhaps to contrast the peculiarities of project managing or designing a creative space (as per Gander). However, there may not be much that Spielberg could directly associate with labour precarity (Farr-Warton, Brown, Keast and Shymko), indigenous creativity (Seet, Jones, Acker and Whittle) or the challenges faced by older workers in the creative industries (Hennekam). That said, an unusual request came to light following the 2014 death of actor Robin Williams. Lord wrote on his website that "he actually had a requirement that, for every single event or film he did, the company hiring him also had to hire a certain number of homeless people and put them to work" Huffington Post (2014). These homeless people may not necessarily be creatives, but the industry could adopt similar policies to reduce their reported levels of labour precarity.

In summary, there seems to be little doubt that management in the Creative Industries requires a degree of ambidexterity, as described by Knight and Harvey. This same ambidexterity is evident in relation to creatives who need to exhibit a range of managerial skills in order to maximise the financial benefit of their efforts. This is a concept which management scholars might adapt for broader contexts where innovation and new approaches for emerging challenges are apparent in the $21^{\text {st }}$ century. In doing so, it might become possible to answer broader questions about management in the creative industries that might include why (or indeed if) we need to reboot the Woolly Mammoth? 


\section{References}

Banks, M. and O'Connor, J. (2009), "After the Creative Industries", International Journal of Cultural Policy, Vol. 15, pp. 365-373.

Boltanski, L. and Chiapello, E. (2005), "The New Spirit of Capitalism", International Journal of Politics, Culture, and Society, Vol. 18, pp. 161-188.

Burgess, J. and Campell, I. (1998), "The Nature and Dimensions of Precarious Employment in Australia", Labour and Industry: A Journal of the Social and Economic Relations of Work, Vol. 8, pp. 5-21.

Chen, T.-Y., Yeh, T.-L., Tu, T.-T. and Wan, T.-W. (2013), "Influence factors of Taiwan sky lantern cultural product: cause and consequence factors of cultural product in cultural and creative industry: a case of sky lantern in Pengxi", Far East Journal of Psychology and Business, Vol. 10, pp. 42-58.

Colquitt, J. A. and Zapata-Phelan, C. P. (2007), :Trends in Theory Building and Theory Testing: A Five-Decade Study of the Academy of Management Journal", Academy of Management Journal, Vol. 50, pp. 1281-1303.

Corley, K. G. and Gioia, D. A. (2011), "Building Theory About Theory Building: What Constitutes a Theoretical Contribution?", Academy of Management Review, Vol. 36, pp. 12-32.

Cunningham, S. (2009), "Trojan Horse or Rorschach Blot? Creative industries discourse around the world", International Journal of Cultural Policy, Vol. 15, pp. 375-386.

Delbridge, R. and Fiss, P. S. (2013), "Styles of Theorizing and the Social Organization of Knowledge", Academy of Management Review, Vol. 38, pp. 325-331.

Galloway, S. and Dunlop, S. (2007), "A Critique of Definitions of the Cultural and Creative Industries in Public Policy", International Journal of Cultural Policy, Vol. 13, pp. 1731.

Hambrick, D. C. (2007), "The Field of Management's Devotion to Theory: Too Much of a Good Thing?", Academy of Management Journal, Volo. 50, pp. 1346-1352.

Hitt, K.G. and Smith, M.A. (2005), "The Process of Developing Management Theory", in Smith, M.A. and Hitt, K.G. (Eds), Great Minds in Management: A Process of Theory Development, Oxford University Press, Oxford.

Hodgson, D. and Briand, L. (2013), "Controlling the Uncontrollable: 'Agile'teams and illusions of autonomy in creative work", Work, Employment and Society, Vol. 27, pp. 308-325.

Huffington Post (2014), "Robin Williams Dead: Actor 'Always Required Film Companies to Hire Homeless People", available at:

www.huffingtonpost.co.uk/channel-search?q=hire+extras\&s_it=aoluk-huffpo-V1 (accessed 19 December 2014). 
Jeffcutt, P. and Pratt, A.C. (2002), "Managing creativity in the Cultural Industries", Creativity and Innovation Management, Vol. 11, pp. 225-233.

Kozlowski, S. W. J. and Klein, K. J. (2000), "A Multilevel Approach to Theory and Research in Organisations: Contextual, Temporal, and Emergent Processes", in Klein K.J. and Kozlowski, S.W.J. (Eds), Multilevel Theory, Research, and Methods on Organisations, Jossey-Bass, San Francisco.

Lepine, J. and King, A. W. (2010), "Editor's Comments: Developing Novel Theoretical Insights from Reviews of Existing Theory and Research", The Academy of Management Review, Vol. 35, pp. 506-509.

McRobbie, A. (2002),"Clubs to Companies: Notes on the Decline of Political Culture in Speeded Up Creative Worlds", Cultural Studies, Vol.16,pp.516-531.

Miller, D. (2007, "Paradigm Prisons, or in Praise of Atheoretic Research", Strategic Organization, Vol. 5, pp. 177-184.

Miller, D., Greenwood, R., and Prakash, R. (2009), "What happened to organization theory?" Journal of Management Inquiry, Vol. 18: 273-279.

Nash Information Services (2015), "The Numbers: Where Data and the Movie Business Meet", available at: http://www.the-numbers.com/movies/franchise/Jurassic-Park (accessed 13 January 2015).

O'Connor, J. (2011), "Economic Development, Enlightenment and Creative Transformation: Creative Industries in the New China", Ekonomiaz: Basque Economic Review, Vol. 78, pp. 108-125.

Poinar, H. (2013), "Bring back the Woolly Mammoth!", available at: www.ted.com/talks/hendrik_poinar_bring_back_the_woolly_mammoth/transcri pt?language $=$ en $($ accessed 15 September 2014).

Powell, P. (2013), "Steven Spielberg making new Halo TV show for XBOX One", Digital Media Academy, available at: www.digitalmediaacademy.org/2013/11/22/steven-spielberg-making-newhalo-tv-show-for-xbox-one (accessed 28 September 2014).

Sutton, R. I. and Staw, B. M. (1995), "What Theory is Not", Administrative Science Quarterly, Vol. 40, pp. 371-384.

Townley, B., Beech, N. and Mckinlay, A. (2009), "Managing in the Creative Industries: Managing the Motley Crew", Human Relations, Vol. 62, pp. 939-962.

Weick, K. E. (1989), "Theory Construction as Disciplined Imagination", Academy of Management Review, Vol. 14, pp. 516-531.

Whetten, D. A. (1989), "What Constitutes a Theoretical Contribution?", Academy of Management Review, Vol. 14, pp. 490-495. 